\title{
Preoperative ejection fraction as a predictor of survival after coronary artery bypass grafting: comparison with a matched general population
}

\author{
Mohamed A Soliman Hamad*1, Albert HM van Straten', Jacques PAM Schönberger'1, Joost F ter Woorst', Andre M de \\ Wolf2, Elisabeth J Martens ${ }^{3,4}$ and André AJ van Zundert5,6
}

\begin{abstract}
Background: Preoperative left ventricular dysfunction is an established risk factor for early and late mortality after revascularization. This retrospective analysis demonstrates the effects of preoperative ejection fraction on the shortterm and long-term survival of patients after coronary artery bypass grafting.

Methods: Early and late mortality were determined retrospectively in 10626 consecutive patients who underwent isolated coronary bypass between January 1998 and December 2007. The subjects were divided into 3 groups according to their preoperative ejection fraction. Expected survival was estimated by comparison with a general Dutch population group described in the database of the Dutch Central Bureau for Statistics. For each of our groups with a known preoperative ejection fraction, a general Dutch population group was matched for age, sex, and year of operation.

Results and Discussion: One hundred twenty-two patients were lost to follow-up. In 219 patients, the preoperative ejection fraction could not be retrieved. In the remaining patients $(n=10285)$, the results of multivariate logistic regression and Cox regression analysis identified the ejection fraction as a predictor of early and late mortality. When we compared long-term survival and expected survival, we found a relatively poorer outcome in all subjects with an ejection fraction of $<50 \%$. In subjects with a preoperative ejection fraction of $>50 \%$, long-term survival exceeded expected survival.
\end{abstract}

Conclusions: The severity of left ventricular dysfunction was associated with poor survival. Compared with the survival of the matched general population, our coronary bypass patients had a worse outcome only if their preoperative ejection fraction was $<50 \%$.

\section{Introduction}

Despite improvement in medical therapies and surgical techniques, the management of patients with coronary artery disease and a low ejection fraction (EF) remains challenging. In patients with a low EF, coronary artery bypass grafting (CABG) has been shown to be superior to medical therapy alone, to produce a statistically significant clinical improvement, and to improve long-term

\footnotetext{
*Correspondence: aasmsn@cze.nl

${ }^{1}$ Department of Cardio-Thoracic Surgery, Catharina Hospital, Eindhoven, The Netherlands

Full list of author information is available at the end of the article
}

survival [1-5]. In such patients, however, CABG is associated with higher postoperative morbidity and mortality rates than those in patients whose left ventricular function is within normal limits [5,6]. In an earlier investigation [7], we showed that superior long-term results after CABG occurred in a group of patients with a low EF $(<$ $40 \%$ ) who were prospectively studied. However, most such reports are limited by inadequate sample size. In this study of patients who underwent CABG, we correlated risk factors and outcomes with preoperative EF and compared the long-term survival of our subjects with that of 
matched cohorts from the general population of The Netherlands.

\section{Methods}

This retrospective study consisted of 10626 patients who underwent isolated CABG performed in the Department of Cardiothoracic Surgery at Catharina Hospital in Eindhoven, The Netherlands, between January 1998 and December 2007. After excluding 122 patients who were lost to follow-up and 219 patients whose the preoperative EF was not retrieved, 10285 patients were evaluated. The study was performed after permission from the local medical ethics committee had been received.

\section{Preoperative EF}

The global EF was determined with 1 or both of following methods: calculation with 2-dimensional echocardiography via the biplane apical method and the modified Simpson's rule [8], and/or ventriculographic evaluation performed by an independent surgeon and an independent cardiologist. The patients were divided into 3 groups as follows: group $1, \mathrm{EF}>50 \%(\mathrm{n}=8204)$; group $2, \mathrm{EF}=$ $35 \%$ to $50 \%(\mathrm{n}=1717)$; group $3, \mathrm{EF}<35 \%(\mathrm{n}=364)$.

\section{Operative techniques}

All patients received short-acting anesthetic drugs to facilitate early extubation. Extracorporeal circulation was performed via a normothermic nonpulsatile flow. Cold crystalloid cardioplegia ("St. Thomas solution") or warmblood cardioplegia was used according to the surgeon's preference to induce and maintain cardioplegic arrest.

\section{Follow-Up}

Follow-up data on mortality were gathered from the databases of health insurance companies, general practitioners, and (if necessary) the governmental authorities. Early mortality was defined as death that occurred from any cause within the first 30 postoperative days, and late mortality was defined as death that occurred more than 30 days after surgery, regardless of cause. For calculating survival of a general population cohort, data were obtained from the Dutch Central Bureau for Statistics (CBS). This is the database registering information about all citizens living in the Netherlands. Every year, a report from the CBS is available online about mortality within the normal population stratified by age and sex. We have matched each group in our study with the general population according to age and sex. Because the incidence of mortality within the general population varies per year, the matching was also done to compare the survival of each group with the survival of the general population for the same year when the studied patients were operated. We considered the survival of the matched general population cohort to represent the expected survival of the patient group.

\section{Statistical analyses}

Discrete variables, which were compared by means of the chi-squared test, are presented as numbers and percentages. Continuous variables were compared by means of the $t$ test and analysis of variance and are presented as the mean \pm standard deviation. Univariate and multivariate logistic regression analyses were performed to investigate the impact of biomedical variables on early mortality. Univariate analyses were used to test potentially confounding effects of biomedical and demographic factors on outcome. The Cox proportional hazard regression analysis was performed to evaluate late mortality. If the $P$ value decreased to $<.05$, then confounding variables were included in the multivariate logistic and Cox regression analyses. Long-term survival was depicted with the Kaplan-Meier method. For comparisons of long-term survival, we used log-rank statistics. "Time zero" was used to designate the time of CABG. The results of timetable analyses were used to describe 5-year and 10-year survival, and comparisons were made with the Wilcoxon test. For all tests, a $P$ value of $<.05$ indicated statistical significance. Hazard ratios are reported with $95 \%$ confidence intervals. All statistical analyses were performed with SPSS software (Statistical Product and Service Solutions, version 15.0, SSPS Inc, Chicago, Illinois).

\section{Results}

The minimum follow-up interval for surviving patients was 60 days. The mean follow-up period was $1696 \pm 1026$ days (range, zero to 3708 days; day zero represented operative death).

The baseline characteristics of patients in the various EF groups are represented in Table 1 . Table 2 shows the operative details of patients in those EF groups. Patients with a low EF (groups 2 and 3) had a longer extracorporeal circulation time than did the other subjects and were more likely to require perioperative intra-aortic balloon pump support than were patients whose EF was within normal limits. There were also fewer off-pump operations in patients with a low EF.

Early and late mortality were statistically significantly higher in patients with a lower EF (Table 3). Risk factors for early mortality identified by univariate and multivariate logistic regression analyses are shown in Table 4. Univariate logistic regression analysis identified preoperative $\mathrm{EF}$ as a risk factor for early mortality. However, the hazard ratio was higher in patients with an EF of $<35 \%$ than in those with an $\mathrm{EF}$ of $35 \%$ to $50 \%$. Other risk factors identified by univariate analysis included age, New York Heart Association class, diabetes, chronic obstructive pulmonary disease (COPD), peripheral vascular disease (PVD), anemia, renal dysfunction, prior cardiac surgery, and emergency operation. Perioperative complications such as myocardial infarction, the need for intra-aortic 
Table 1: Preoperative characteristics of the study subjects*.

\begin{tabular}{|c|c|c|c|c|}
\hline Variables & $\begin{array}{l}\text { Group } 1 \\
(E F>50 \%) \\
(n=8204)\end{array}$ & $\begin{array}{l}\text { Group } 2 \\
(E F=35 \%-50 \%) \\
(n=1717)\end{array}$ & $\begin{array}{l}\text { Group } 3 \\
(E F<35 \%) \\
(n=364)\end{array}$ & $P$ Value \\
\hline Age $(y)($ mean $\pm S D)$ & $64.5 \pm 9.5$ & $65.0 \pm 9.7$ & $65.6 \pm 8.9$ & 0.014 \\
\hline Male sex (\%) & $6254(76.2)$ & $1382(80.5)$ & $297(81.6)$ & $<0.0001$ \\
\hline NYHA class III or IV (\%) & $436(5.3)$ & $142(8.3)$ & $53(14.6)$ & $<0.0001$ \\
\hline Angina class (mean \pm SD) & $2.7 \pm 1.2$ & $2.6 \pm .3$ & $2.3 \pm 1.5$ & 0.012 \\
\hline Hypertension (\%) & $3554(43.3)$ & $649(37.8)$ & $127(34.9)$ & $<0.0001$ \\
\hline COPD (\%) & $987(12.0)$ & $258(15.0)$ & $58(15.9)$ & $<.0001$ \\
\hline Diabetes (\%) & $1692(20.6)$ & $413(24.1)$ & $96(26.4)$ & $<0.0001$ \\
\hline 1 Prior MI (\%) & $2635(32.3)$ & $1016(59.3)$ & $204(56.0)$ & $<0.0001$ \\
\hline 2 Prior Mls (\%) & $280(3.4)$ & $167(9.7)$ & $55(15.1)$ & $<0.0001$ \\
\hline > 2 Prior Mls (\%) & $25(0.3)$ & $15(0.9)$ & $6(1.6)$ & $<0.0001$ \\
\hline $\mathrm{CrCl}<60 \mathrm{~mL} / \mathrm{min}(\%)$ & $2168(27.4)$ & $568(34.4)$ & $152(44.4)$ & $<0.0001$ \\
\hline PVD (\%) & $908(11.1)$ & 239 (13.9) & $51(14.0)$ & 0.002 \\
\hline Emergency (\%) & $237(2.9)$ & $71(4.1)$ & $33(9.1)$ & $<0.0001$ \\
\hline Prior cardiac surgery (\%) & $384(4.7)$ & $154(9.0)$ & $39(10.7)$ & $<0.0001$ \\
\hline
\end{tabular}

balloon pump support, and re-exploration were also identified as risk factors for early mortality.

All preoperative risk factors identified by univariate analysis were entered in the multivariate logistic regression model. A low EF proved to be an independent risk factor for early mortality. Other factors were age, diabetes, COPD, renal dysfunction, prior cardiac surgery, and emergency operation.
The results of Cox regression analysis to identify risk factors for late mortality are shown in Table 5 . Univariate analysis identified preoperative $\mathrm{EF}$ as a risk factor for late mortality. Other significant risk factors were age, sex, New York Heart Association class, hypertension, anemia, COPD, diabetes, renal dysfunction, PVD, and prior cardiac surgery. When those factors were entered into the multivariate analysis, a low EF proved to be an indepen-

Table 2: Operative details of the study subjects*.

\begin{tabular}{|c|c|c|c|c|}
\hline Variables & $\begin{array}{l}\text { Group } 1 \\
(E F>50 \%) \\
(n=8204)\end{array}$ & $\begin{array}{l}\text { Group } 2 \\
(E F=35 \%-50 \%) \\
(n=1717)\end{array}$ & $\begin{array}{l}\text { Group } 3 \\
(E F<35 \%) \\
(n=364)\end{array}$ & PValue \\
\hline Off-pump (\%) & $780(9.5)$ & $101(5.9)$ & $21(5.8)$ & $<0.0001$ \\
\hline IMA (\%) & $7378(89.9)$ & $1494(87.0)$ & $277(76.1)$ & $<0.0001$ \\
\hline No. anastomoses (mean \pm SD) & $3.42 \pm 1.1$ & $3.5 \pm 1.1$ & $3.62 \pm 1.1$ & 0.295 \\
\hline \multicolumn{5}{|l|}{ Cardioplegia: } \\
\hline Crystalloid (\%) & $2432(36.4)$ & $479(38.1)$ & $118(42.0)$ & $<0.001$ \\
\hline Blood (\%) & $3299(49.35)$ & $652(51.9)$ & $133(47.3)$ & $<0.001$ \\
\hline $\mathrm{ECC}$ time (min) (mean $\pm \mathrm{SD})$ & $56.5 \pm 32.7$ & $61.9 \pm 31.0$ & $68.0 \pm 35.8$ & $<0.001$ \\
\hline Re-exploration (\%) & $428(5.2)$ & $119(6.9)$ & 13(3.6) & 0.009 \\
\hline Perioperative MI (\%) & $240(2.9)$ & $49(2.9)$ & $12(3.3)$ & 0.775 \\
\hline IABP (\%) & $121(1.5)$ & $56(3.3)$ & $30(8.2)$ & $<0.0001$ \\
\hline
\end{tabular}

$\mathrm{EF}=$ Ejection fraction, $\mathrm{IMA}=$ internal mammary artery, $\mathrm{ECC}=$ extracorporeal circulation, $\mathrm{MI}=$ myocardial infarction, $\mathrm{IABP}=$ intra-aortic balloon pump support.

${ }^{*}$ Data are represented as the number (\%) or mean \pm SD. 
Table 3: Early and late mortality according to preoperative ejection fraction.

\begin{tabular}{|c|c|c|c|c|}
\hline Variables & $\begin{array}{l}\text { Group } 1 \\
(E F>50 \%) \\
(n=8204)\end{array}$ & $\begin{array}{l}\text { Group } 2 \\
(E F=35 \%-50 \%) \\
(n=1717)\end{array}$ & $\begin{array}{l}\text { Group } 3 \\
(E F<35 \%) \\
(n=364)\end{array}$ & P Value \\
\hline Early mortality (\%) & $129(1.6)$ & $63(3.7)$ & $38(10.5)$ & $<.0001$ \\
\hline Late mortality (\%) & $742(9.1)$ & $296(17.4)$ & $81(22.4)$ & $<.0001$ \\
\hline
\end{tabular}

dent risk factor for late mortality. Other statistically significant factors were age, sex, New York Heart Association class, diabetes, COPD, renal dysfunction, anemia, PVD, and prior cardiac surgery.

Figure 1 shows long-term survival stratified by preoperative EF. The log-rank test yielded a $P$ value of $<.0001$, which indicates statistically significant differences in long-term survival among all groups. Patients in group 1 $(\mathrm{EF}>50 \%)$ had greater long-term survival than that expected $(P<.0001)$. However, the long-term survival of patients in both group $2(\mathrm{EF}=35-50 \%)$ and group $3(\mathrm{EF}<$ $35 \%)$ was worse than the expected survival $(P<.0001$; log-rank test). One-year, 5-year and 10-year survival differed among patient groups (Wilcoxon test $P$ value < .0001) (Table 6).

\section{Discussion}

The main finding of this study was that preoperative EF is a statistically significant predictor for higher rates of early and late mortality after CABG. Patients with a low EF had

Table 4: Univariate and multivariate logistic regression analyses of risk factors for early mortality in the study subjectst.

\begin{tabular}{|c|c|c|c|c|}
\hline Risk factors & $\begin{array}{l}\text { OR early mortality } \\
\text { Univariate analysis }\end{array}$ & P value & $\begin{array}{l}\text { OR early mortality } \\
\text { Multivariate analysis }\end{array}$ & P value \\
\hline$E F 35 \%-50 \%$ & $2.623(1.923-3.578)$ & $<.0001$ & $1.9(1.335-12.693)$ & $<.0001$ \\
\hline $\mathrm{EF}<35 \%$ & $7.592(5.143-11.207)$ & $<.0001$ & $4.206(2.6-6.805)$ & $<.0001$ \\
\hline Age $(y)^{*}$ & $1.08(1.062-1.098)$ & $<.0001$ & $1.031(1.004-1.059)$ & .026 \\
\hline Male sex & $0.802(0.601-1.070)$ & .071 & & \\
\hline NYHA class & $1.338(1.122-1.595)$ & .001 & $1.168(0.908-1.503)$ & .227 \\
\hline Angina class & $1.002(0.951-1.055)$ & .277 & & \\
\hline Hypertension & $0.929(0.716-1.207)$ & .662 & & \\
\hline COPD & $1.966(1.438-2.687)$ & $<.0001$ & $1.479(0.943-2.319)$ & .089 \\
\hline Preoperative $\mathrm{Hb}$ level & $0.692(0.634-0.755)$ & $<.0001$ & $0.883(0.779-1.001$ & .051 \\
\hline Diabetes & $1.524(1.148-2.023)$ & .004 & $1.743(1.195-2.543)$ & .004 \\
\hline Preoperative $\mathrm{CrCl}$ & $0.965(0.962-0.968)$ & $<.0001$ & $0.978(0.967-0.988)$ & $<.0001$ \\
\hline PVD & $1.633(1.164-2.290)$ & .005 & $1.441(991-2.277)$ & .118 \\
\hline Prior cardiac surgery & $4.542(3.304-6.244)$ & $<.0001$ & $3.064(1.847-5.083)$ & $<.0001$ \\
\hline No. of anastomoses & $0.903(0.801-1.011)$ & .077 & & \\
\hline Off-pump & $0.631(0.366-1.087)$ & .097 & & \\
\hline Use of IMA & $0.231(0.176-0.303)$ & $<.001$ & & \\
\hline Cardioplegia & $1.312(0.995-1.731)$ & .054 & & \\
\hline Emergency & $6.550(4.722-9.087)$ & $<.0001$ & $3.307(1.597-6.846)$ & .001 \\
\hline Perioperative MI & $5.938(4.053-8.699)$ & $<.0001$ & & \\
\hline Re-exploration & $5.810(4.261-7.922)$ & $<.0001$ & & \\
\hline IABP & $13.974(9.916-19.691)$ & $<.0001$ & & \\
\hline
\end{tabular}

$\mathrm{OR}=$ Odds ratio, $\mathrm{EF}=$ ejection fraction, $\mathrm{NYHA}=$ New York Heart Association, $\mathrm{COPD}=$ chronic obstructive pulmonary disease, Hb $=$ hemoglobin, $\mathrm{CrCl}=$ creatinine clearance, $\mathrm{PVD}=$ peripheral vascular disease, $\mathrm{IMA}=$ internal mammary artery, $\mathrm{MI}=\mathrm{myocardial}$ infarction, IABP = intra-aortic balloon pump support.

† Only preoperative variables which are significant in the univariate analysis were entered into the multivariate analysis

*Entered as a continuous variable. 
Table 5: Univariate and multivariate Cox regression analyses of risk factors for late mortality†.

\begin{tabular}{|c|c|c|c|c|}
\hline Risk factor & $\begin{array}{l}\text { HR late mortality } \\
\text { Univariate analysis }\end{array}$ & P value & $\begin{array}{l}\text { HR late mortality } \\
\text { Multivariate analysis }\end{array}$ & P value \\
\hline EF $35 \%-50 \%$ & $1.866(1.614-2.157)$ & $<.0001$ & $1.562(1.339-1.822)$ & $<.0001$ \\
\hline $\mathrm{EF}<35 \%$ & $2.859(2.231-3.665)$ & $<.0001$ & $1.051(0.924-1.196)$ & $<.0001$ \\
\hline Age $(y)^{*}$ & $1.094(1.086-1.103)$ & $<.0001$ & $1.067(1.053-1.081)$ & $<.0001$ \\
\hline Male sex & $0.835(0.726-0.961)$ & .012 & $1.629(1.346-1.97)$ & $<.0001$ \\
\hline NYHA class & $1.201(1.094-1.318)$ & $<.0001$ & $1.501(1.267-1.779)$ & $<.0001$ \\
\hline Angina class & $1.002(0.951-1.055)$ & .95 & & \\
\hline Hypertension & $1.223(1.079-1386)$ & .002 & $1.137(0.971-1.33)$ & .11 \\
\hline COPD & $1.778(1.523-2.077)$ & $<.0001$ & $1.473(1.211-1.792)$ & $<.0001$ \\
\hline Diabetes & $1.733(1.512-1.985)$ & $<.0001$ & $1.526(1.287-1.809)$ & $<.0001$ \\
\hline Preoperative $\mathrm{CrCl}$ & $0.965(0962-0.968)$ & $<.0001$ & $0.986(0.981-0.992)$ & $<.0001$ \\
\hline PVD & $2.307(1.978-2.690)$ & $<.0001$ & $1.699(1.397-2.066)$ & $<.0001$ \\
\hline Preoperative $\mathrm{Hb}$ & $0.743(0.711-0.777)$ & $<.0001$ & $0.867(0.816-0.922)$ & $<.0001$ \\
\hline Prior cardiac surgery & $1.536(1.248-1.891)$ & $<.0001$ & $1.143(0.851-1.536)$ & .374 \\
\hline Emergency & $1.268(0.957-1.681)$ & .099 & & \\
\hline No. of anastomoses & $1.089(1.032-1.148)$ & .002 & & \\
\hline Use of IMA & $0.544(0.465-0.637)$ & $<.0001$ & & \\
\hline Off-pump & $0.76(0.58-0.996)$ & .046 & & \\
\hline Perioperative MI & $1.801(1.331-2.437)$ & $<.0001$ & & \\
\hline Re-exploration & $1.673(1.344-2.082)$ & $<.0001$ & & \\
\hline IABP & $1.903(1.364-2.655)$ & $<.0001$ & & \\
\hline
\end{tabular}

$\mathrm{HR}=$ Hazard ratio, $\mathrm{EF}=$ ejection fraction, $\mathrm{NYHA}=$ New York Heart Association, $\mathrm{COPD}=$ chronic obstructive pulmonary disease, $\mathrm{CrCl}=$ creatinine clearance, $\mathrm{PVD}=$ peripheral vascular disease, $\mathrm{Hb}=$ hemoglobin, IMA = internal mammary artery, $\mathrm{MI}=$ myocardial infarction, IABP = intra-aortic balloon pump support.

† Only preoperative variables which are significant in the univariate analysis were entered into the multivariate analysis *Entered as a continuous variable.

a worse survival than did patients whose EF was within normal limits. Revascularization in patients with a low EF has been reported by several authors to be superior to medical therapy. Alderman and colleagues [1] showed that patients with an EF of $\leq 35 \%$ who were treated with medical management had a $43 \% 5$-year survival rate as opposed to a $63 \%$ 5-year survival rate in the surgically treated patients. Although CABG enables longer survival and a better quality of life than does medical therapy, the postsurgical outcomes of patients with a low EF have been shown to be considerably worse than those in patients with a high EF $[3,6]$.

A low EF has been shown to be an independent risk factor for high operative mortality $[9,10]$. In our study, we noted that the early mortality rate in patients with an EF of $<35 \%$ was more than 6 times higher than that in patients with an EF of $>50 \%(10.5 \%$ vs $1.6 \%)$. This finding supports the results of other studies on the initial effect of isolated CABG on mortality in patients with a low EF. Di Carli and colleagues [4] reported a 9.3\% 30-day mortality rate in patients with an EF of $<40 \%$. Christakis and colleagues [6] demonstrated a $9.8 \%$ operative mortality rate in patients with an EF of $<20 \%$, and a study by Carr and colleagues [11] demonstrated an $11 \%$ perioperative mortality rate in patients with an EF between $10 \%$ and $20 \%$. However, more recent reports have shown lower operative mortality rates. In a review of the New York State database [12], the early mortality rate of patients with an EF of $\leq 20 \%$ was $4.6 \%$. Another report showed an in-hospital mortality rate of $4 \%$ in patients with an EF of $<30 \%$ [13]. In an earlier report, we found approximately the same in-hospital mortality rate $(4 \%)$ in 75 prospectively studied patients with an EF of $<40 \%$ [14]. The decline of those mortality rates over time showed a statistically significant improvement from the double-digit rates reported in the 1980s. We suggest that improvements in cardiac anesthesia, perioperative care, surgical techniques, emergency cardiac care, and postoperative management contribute significantly to more encouraging outcomes. 


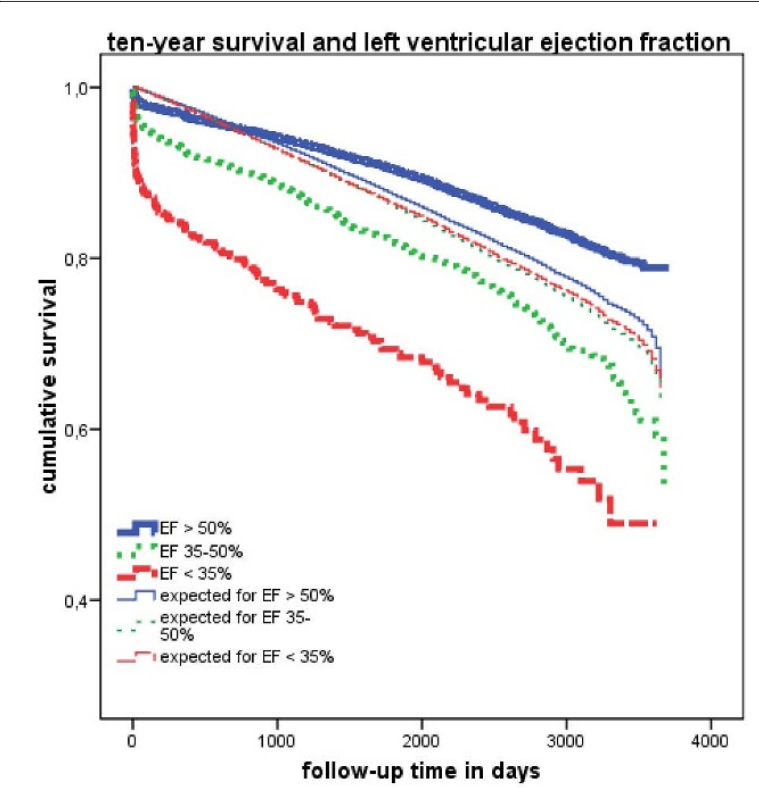

Figure 1 Kaplan-Meier curve of study groups and their expected survival.

Patients with impaired left ventricular function who undergo CABG are a distinctive group of patients. Their risk factors that increase the postoperative mortality rate may not be similar to risk factors usually found in patients whose EF is within normal limits. Christakis and colleagues [6] observed that the urgency of surgery was the only independent predictor of operative mortality in patients with an EF of $<20 \%$ who underwent CABG. Other authors [15] have reported that an age of $>70$ years was the only independent predictor of in-hospital mortality in patients with an EF of $\leq 30 \%$ who underwent CABG. Hausmann and colleagues [16] noted that increased left ventricular end diastolic pressures, decreased cardiac index, and New York Heart Association class were univariate predictors of operative mortality in patients with an EF of $<30 \%$. Argenziano and colleagues [17] found that reoperation and congestive heart failure were predictors of perioperative mortality in patients with an $\mathrm{EF}$ of $\leq 35 \%$. In our study, patients with a low EF had a higher incidence of preoperative comorbid conditions such as diabetes, New York Heart Association class III or IV, COPD, renal dysfunction, PVD, and/or reoperation than did those with normal EF. Those factors may have contributed to the higher incidence of early mortality in patients with low EF. Using multivariate logistic regression analysis, we found age, New York Heart Association class, renal dysfunction, COPD, diabetes, reoperation, and emergency operation to be statistically significant predictors of in-hospital mortality.

The results of our study confirmed that patients with a lower EF have a poorer long-term outcome than do patients whose EF is within normal limits. We found that in patients with an EF of $<35 \%$, the 5 -year survival rate was $64.8 \%$, and the 10 -year survival rate was $44.7 \%$. Those statistics compare favorably with the results of medical treatment, even in the current era of aggressive use of angiotensin-converting enzyme inhibitors and other medications for congestive heart failure [18]. In some studies, complete revascularization of the ischemic myocardium had a major impact on long-term survival, even when viability was not consistently documented. Shapira and colleagues [19] noted a 5 -year survival of $76 \%$ in patients with an $\mathrm{EF}$ of $<30 \%$ who underwent CABG. Similar results were reported by other investigators [9,20-23]. The number of studies addressing 10-year survival in such patients, however, is limited. In a study by Shah and colleagues [20], the 5-year survival rate in patients with an $\mathrm{EF}$ of $<35 \%$ was $55 \%$, and the 10 -year survival rate was $23.9 \%$. In a recent study of patients with an $\mathrm{EF}$ of $\leq 30$, approximately $80 \%$ were alive 5 years after surgery, and $45 \%$ were alive 10 years after surgery [24]. A 20 -year survival study by Weintraub and colleagues showed that a low EF independently predicted poor long-term survival after CABG, although the subjects experienced good relief from angina [25].

Like other authors $[20,21]$, we observed that age and male sex are independent predictors of long-term outcome in patients undergoing CABG. Other important predictors were New York Heart Association class, COPD, anemia, renal dysfunction, diabetes, and PVD. Bouchart and colleagues [10] identified the following statistically significant predictors of long-term survival after CABG in patients with an EF of $\leq 20 \%$ : a chief complaint of only pain, unstable angina, and a Canadian and New York Heart Association class lower than IV.

Case selection has been shown to be an important factor in achieving a favorable outcome after CABG in patients with a low EF [24]. Our study included patients without preoperative viability test results and those with

Table 6: Survival rates (\%) for 1, 5, and 10 years, stratified by preoperative ejection fraction (EF).

\begin{tabular}{llll}
\hline & 1-year & 5-year & 10-year \\
\hline Group 1 $(\mathrm{EF}>50 \%)$ & $95.1 \pm 0.2$ & $87.9 \pm 0.4$ & $78.6 \pm 0.9$ \\
Group 2 $(\mathrm{EF}=35-50 \%)$ & $90.0 \pm 0.8$ & $78.9 \pm 0.12$ & $50.7 \pm 6.8$ \\
Group 3 $(\mathrm{EF}<35 \%)$ & $79.0 \pm 2.2$ & $64.8 \pm 2.9$ & $44.7 \pm 6.5$ \\
\hline
\end{tabular}


a ventricular aneurysm or associated mild or moderate mitral regurgitation. Di Carli and colleagues [4] showed that in patients evaluated with positron emission tomography, those who had an EF of $<40 \%$ and a viable myocardium had a better 4-year survival rate than did patients without evidence of a viable myocardium.

A rather unique feature of our study is that we compared the survival of our patients with that of a cohort of the general Dutch population matched for age, sex, and year of operation. Over the years, variation in life expectancy and mortality rates of the Dutch population has been well documented by the Dutch Central Bureau for Statistics. We used data from the Central Bureau for Statistics to compare survival of our patients with the survival of general population cohorts matched for age and sex (expected survival). We found that patients with a low EF had worse long-term survival than that their matched cohort of the Dutch citizens. Patients whose EF was within normal limits had better long-term survival than that in the matched cohort of the general Dutch population. Although that information does not guide surgical decision making, it may be relevant for patients with regard to their long-term prognosis. Nevertheless, those findings must be interpreted with caution, because the Dutch Central Bureau for Statistics database includes data from the entire Dutch population. As a result, data from the patients described in this study as well as data from patients treated in other cardiac surgery centers are included. In patients who underwent CABG, the protection provided by revascularization, the postoperative medical therapy administered to treat hypertension and hypercholesterolemia, and the use of antiplatelet therapy may increase the bias. In addition, patients who are scheduled to undergo CABG receive preoperative screening for, and treatment of underlying diseases that may contraindicate surgery. Perhaps for those reasons, survival in patients whose EF was within normal limits was longer than the expected survival in the matched cohort of the normal general population.

\section{Limitations of the study}

Like most similar reports, our study was based on the retrospective evaluation of patient charts. To prove the usefulness of a surgical procedure, a study must be prospective, controlled, and randomized. However, we suggest that the relatively large number of patients in our report justifies our conclusions. The primary endpoint of the study was all-cause mortality. We were not able to retrieve the cause of death in both groups which could be equally important. Information about the quality of life of the surviving patients, their eventual symptoms, and their incidence of rehospitalization; residual mitral regurgitation; the recurrence of congestive heart failure; and other possible complications is lacking. We recommend cau- tion in interpreting the results of the comparison with the general population. The Central Bureau for Statistics database includes the total Dutch population. Therefore, data of the patients described in this study and of those treated at other Dutch cardiac surgery centers are also included in the CBS databse. Because of this, the magnitude of differences between groups tends to be lessened. The annual number of patients undergoing CABG in the Netherlands is small, (10 000 patients), compared to the total number of the general population, limiting the effect of this inaccuracy. Clinical information including data about the EF is missing in the general population group. However, the results of our study can help in informing patients with normal preoperative EF that their prognosis after CABG is favourable.

\section{Conclusions}

This study confirmed that a low EF is a predictive risk factor for early and late mortality after CABG. Patients whose EF was within normal limits (ie, $>50 \%$ ) had better long-term survival than that in a matched cohort of the general Dutch population, but patients with a low EF (ie, $<50 \%)$ had a worse long-term survival than that in their respective matched cohort.

\section{Authors' contributions}

MSH: Participated in the design of the study, writing the manuscript and performed the revisions. AvS: participated in the design of the study, performing the statistical analysis, and writing the manuscript. JS: participated in writing and revising the manuscript. JtW: participated in writing the manuscript. AdW participated in writing the manuscript. EM: participated in the statistical analysis. AvZ: participated in writing and revising the manuscript. All authors read and approved the final manuscript.

\section{Competing interests}

The authors declare that they have no competing interests.

\section{Author Details}

'Department of Cardio-Thoracic Surgery, Catharina Hospital, Eindhoven, The Netherlands, ${ }^{2}$ Department of Anesthesiology, The Feinberg School of Medicine, Northwestern University, Chicago, Illinois, USA, ${ }^{3}$ Department of Education and Research, Catharina Hospital, Eindhoven, the Netherlands, ${ }^{4}$ Center of Research on Psychology in Somatic diseases, Department of Medical Psychology, Tilburg University, the Netherlands, ${ }^{5}$ Department of Anesthesiology, Catharina Hospital - Brabant Medical School, Eindhoven, the Netherlands and 6 University Hospital Ghent, Ghent, Belgium

Received: 17 November 2009 Accepted: 23 April 2010

Published: 23 April 2010

\section{References}

1. Alderman EL, Fisher LD, Litwin P, Kaiser GC, Myers WO, Maynard C, Levine $F$, Schloss M: Results of coronary artery surgery in patients with poor left ventricular function (CASS). Circulation 1983, 68(4):785-795.

2. Passamani E, Davis KB, Gillespie MJ, Killip T: A randomized trial of coronary artery bypass surgery. Survival of patients with a low ejection fraction. NEng/ J Med 1985, 312(26):1665-1671.

3. Scott SM, Deupree RH, Sharma GV, Luchi RJ:VA Study of unstable angina. 10-year results show duration of surgical advantage for patients with impaired ejection fraction. Circulation 1994, 90(5 Pt 2):II120-II123.

4. Di Carli MF, Maddahi J, Rokhsar S, Schelbert HR, Bianco-Batlles D, Brunken $\mathrm{RC}$, Fromm B: Long-term survival of patients with coronary artery disease and left ventricular dysfunction: implications for the role of 
myocardial viability assessment in management decisions. J Thorac Cardiovasc Surg 1998, 116(6):997-1004.

5. Zubiate P, Kay JH, Mendez AM: Myocardial revascularization for the patient with drastic impairment of function of the left ventricle. $J$ Thorac Cardiovasc Surg 1977, 73(1):84-86.

6. Christakis GT, Weisel RD, Fremes SE, Ivanov J, David TE, Goldman BS, Salerno TA: Coronary artery bypass grafting in patients with poor ventricular function. Cardiovascular Surgeons of the University of Toronto. J Thorac Cardiovasc Surg 1992, 103(6):1083-1091. discussion 1091-1092.

7. Soliman Hamad MA, Tan ME, van Straten AH, van Zundert AA, Schönberger JP: Long-term results of coronary artery bypass grafting in patients with left ventricular dysfunction. Ann Thorac Surg 2008, 85(2):488-493.

8. Weiss JL, Eaton LW, Kallman CH, Maughan WL: Accuracy of volume determination by two-dimensional echocardiography: defining requirements under controlled conditions in the ejecting canine left ventricle. Circulation 1983, 67(4):889-895.

9. Trachiotis GD, Weintraub WS, Johnston TS, Jones EL, Guyton RA, Craver $J \mathrm{M}$ : Coronary artery bypass grafting in patients with advanced left ventricular dysfunction. Ann Thorac Surg 1998, 66(5):1632-1639.

10. Bouchart F, Tabley A, Litzler PY, Haas-Hubscher C, Bessou JP, Soyer R: Myocardial revascularization in patients with severe ischemic left ventricular dysfunction. Long term follow-up in 141 patients. Eur J Cardiothorac Surg 2001, 20(6):1157-1162.

11. Carr JA, Haithcock BE, Paone G, Bernabei AF, Silverman NA: Long-term outcome after coronary artery bypass grafting in patients with severe left ventricular dysfunction. Ann Thorac Surg 2002, 74(5):1531-1536.

12. Topkara VK, Cheema FH, Kesavaramanujam S, Mercando ML, Cheema AF Namerow PB, Argenziano M, Naka Y, Oz MC, Esrig BC: Coronary artery bypass grafting in patients with low ejection fraction. Circulation 2005, 112(9 Suppl):1344-1350.

13. Ascione R, Narayan P, Rogers CA, Lim KH, Capoun R, Angelini GD: Early and midterm clinical outcome in patients with severe left ventricular dysfunction undergoing coronary artery surgery. Ann Thorac Surg 2003, 76(3):793-799.

14. Soliman Hamad MA, Peels K, Van Straten A, Van Zundert A, Schönberger J: Coronary artery bypass surgery in patients with impaired left ventricular function. Predictors of hospital outcome. Acta Anaesthesiol Belg 2007, 58(1):37-44

15. Lslamoglu F, Apaydin AZ, Posacioglu H, Ozbaran M, Hamulu A, Buket S, Telli A, Durmaz I: Coronary artery bypass grafting in patients with poor left ventricular function. Jpn Heart J 2002, 43(4):343-356.

16. Hausmann $\mathrm{H}$, Topp $\mathrm{H}$, Siniawski $\mathrm{H}$, Holz S, Hetzer R: Decision-making in end-stage coronary artery disease: revascularization or heart transplantation? Ann Thorac Surg 1997, 64(5):1296-1301. discussion 1302

17. Argenziano M, Spotnitz HM, Whang W, Bigger JT Jr, Parides M, Rose EA: Risk stratification for coronary bypass surgery in patients with left ventricular dysfunction: analysis of the coronary artery bypass grafting patch trial database. Circulation 1999, 100(19 Suppl):II1 19-II124

18. Gheorghiade M, Bonow RO: Chronic heart failure in the United States: a manifestation of coronary artery disease. Circulation 1998 97(3):282-289

19. Shapira OM, Hunter CT, Anter E, Bao Y, DeAndrade K, Lazar HL, Shemin RJ: Coronary artery bypass grafting in patients with severe left ventricular dysfunction--early and mid-term outcomes. J Card Surg 2006, 21(3):225-232.

20. Shah PJ, Hare DL, Raman JS, Gordon I, Chan RK, Horowitz JD, Rosalion A, Buxton BF: Survival after myocardial revascularization for ischemic cardiomyopathy: a prospective ten-year follow-up study. J Thorac Cardiovasc Surg 2003, 126(5):1320-1327.

21. Luciani GB, Montalbano G, Casali G, Mazzucco A: Predicting long-term functional results after myocardial revascularization in ischemic cardiomyopathy. J Thorac Cardiovasc Surg 2000, 120(3):478-489.

22. Mickleborough LL, Carson S, Tamariz M, Ivanov J: Results of revascularization in patients with severe left ventricular dysfunction. $J$ Thorac Cardiovasc Surg 2000, 119(3):550-557.

23. Appoo J, Norris C, Merali S, Graham MM, Koshal A, Knudtson ML, Ghali WA: Long-term outcome of isolated coronary artery bypass surgery in patients with severe left ventricular dysfunction. Circulation 2004, 110(11 Suppl 1):|l13-117.
24. Lee S, Chang BC, Yoo KJ, Hong YS, Kang MS: Clinical results of coronary revascularization in left ventricular dysfunction. Circ J 2007 71(12):1862-1866.

25. Weintraub WS, Clements SD Jr, Crisco LV, Guyton RA, Craver JM, Jones EL, Hatcher CR Jr: Twenty-year survival after coronary artery surgery: an institutional perspective from Emory University. Circulation 2003, 107(9):1271-1277.

doi: 10.1186/1749-8090-5-29

Cite this article as: Soliman Hamad et al., Preoperative ejection fraction as a predictor of survival after coronary artery bypass grafting: comparison with a matched general population Journal of Cardiothoracic Surgery 2010, 5:29

\section{Submit your next manuscript to BioMed Central and take full advantage of:}

- Convenient online submission

- Thorough peer review

- No space constraints or color figure charges

- Immediate publication on acceptance

- Inclusion in PubMed, CAS, Scopus and Google Scholar

- Research which is freely available for redistribution

Submit your manuscript at www.biomedcentral.com/submit
C Biomed Central 